\title{
A RAILWAY WHEELSET OPTIMALLY DESIGNED FOR COLD PRESS FITTING
}

\author{
Giampiero Mastinu ${ }^{a}$, Massimiliano Gobbi $^{b}$, Alessandro Bon $^{c}$ \\ ${ }^{a}$ Department of Mechanical Engineering, Politecnico di Milano, via G. La Masa 34, 20158 Milano Italy, e-mail: \\ mastinu@mecc.polimi.it \\ ${ }^{b}$ Department of Mechanical Engineering, Politecnico di Milano, via G. La Masa 34, 20158 Milano Italy, e-mail: \\ gobbi@mecc.polimi.it \\ ${ }^{c}$ now with: Alstom Ferroviaria s.p.a., via Ottavio Moreno 23, 12038 Savigliano (Cuneo) Italy, e-mail: \\ alessandro.bon@transport.alstom.com
}

\begin{abstract}
In the present paper, the study of the press fitting of railway wheels is studied with the aim to define the mechanical and physical parameters to be adopted in order to reduce as much as possible the damaging of both wheel and axle during repeated press fitting and wheel removals.

The study has been performed in a theoretical way, through a new multi-objective optimisation method based on finite element analyses. The FEM model has been validated.

Referring to an actual case, the parameters that influence the press fitting process have been determined. The parameters influence was related not only to the mechanical stresses into the structures of the wheel and the axle respectively, but also to the robustness of the design (sensitivity to the machining tolerances and to friction coefficient at the press fit surfaces). Some optimal solutions have been determined and compared (in terms of performances) with an actual production one.
\end{abstract}

\section{INTRODUCTION}

The press fitting process of a railway wheel is still today a topic for scientific research [1-4]. Many guidelines and standards have been issued on the topic [4-10], but still some important aspects are to be clarified. Actually, the contact stresses between wheel and axle, especially during the press fitting phase, are relatively complicated to be analysed by calculation. In the wheel/hub contact zone the lubricant interacts with the peaks of the surface roughness of the mating surfaces in a way very hard to be modelled. A mathematical model that simulates the press fitting process is still to be validated in an exhaustive manner, although in [3] a first attempt has been performed with success.

In this paper, the problem to design the wheel and the axle in the hub zone is addressed, in order to keep as low as possible the mechanical stresses during both the press fitting and the removal of the wheel from its seating. In fact, the press fitting of a wheel and the removal of the wheel from its seating are performed several times during the typical life span of a wheelset.
The authors argue that the numerical simulation of the press shrinking process is still not fully reliable and therefore only an accurate and extensive experimental analysis may allow to define the geometric parameters and, more generally, mechanics and physics that optimise the mechanical behaviour of the press shrinking of a railway wheel on its axle.

In the present work the problem of wheel and axle design in the zone of the mating surfaces has been studied with the aim to reach an adequate safety level and to minimise the mechanical stresses during the press-fitting phase. To obtain the aforementioned goals a theoretical preliminary study has been carried out (with the constraints explained before) to simulate the press fitting and the removal of a wheel from its seating. The developed mathematical model has been validated with satisfactory results. By the theoretical simulations, some 'response surfaces' [14-16] have been determined to establish the mathematical relationships between the design variables and the press fitting performance indices. Through the use of such response surfaces the design optimisation has been performed. Much attention has been paid in finding those solutions which were optimal and robust, i.e. the solutions being insensitive to the uncontrolled variations affecting some parameters of the press shrinking process, as friction and the interference between wheel bore and axle diameter. The obtained results can be considered as a preliminary contribution, very useful to define the goals of a further extensive experimental research aiming to optimally design the press fitting of railway wheels.

\section{MODEL}

The wheel and the axle can be considered symmetric with respect to their axis. Also the orientation of the forces during the press fitting are substantially symmetric with respect to the wheel axis, so in the FEM modelling, axial symmetric elements (Fig. 1) were adopted. Patran v.8.5, and Abaqus v.5.8 have been employed to perform FEM analysis. Two types of finite elements were used: CAX3 (triangular shaped elements with three nodes and one integration point per element) and CAX4R (four side with four nodes and 
reduced integration, with only one integration point per element). The whole model (wheel plus axle) has 15678 nodes and 15267 elements. The axle model has 12477 nodes and 12173 elements, the mesh is refined in the wheel seat zone where the maximum values of stress and related gradients are foreseen. The wheel model has 2981 nodes and 2904 elements. The mesh is refined at the wheel bore. The contact surfaces, on the wheel bore and on the wheel seat on the axle, have been carefully meshed in order to simulate the stresses applied between the two parts during the press fitting process [11-12]; the two contact surfaces have been classified as master and slave, to simulate the interference ISO H7u6.

The press fitting simulation has been subdivided into 23 steps, each of them representing a fixed position of the wheel with respect to the axle, as shown in Tab.1. For each step, the number of finite elements of wheel and axle being in contact has been defined, varying the models of slave and master surfaces. The imposed thrust of the hydraulic press on the wheel to fit it onto the axle has been simulated by imposing a fixed amplitude displacement (as reported in Tab.1) to the nodes representing the hydraulic press. In the actual workshop practice, a determined magnitude of force is imposed through the hydraulic press and during the press shrinking process the gradient of the force is monitored to record any change (if there is a sudden great increase, that is symptom of the occurrence of a seizure, the press shrinking is stopped [10]).

For the press fitting simulation purposes the materials of the wheel and the axle have been considered as isotropic with ideal elastic-plastic behaviour (as shown in Fig.2 diagram $\sigma-\varepsilon$ ).

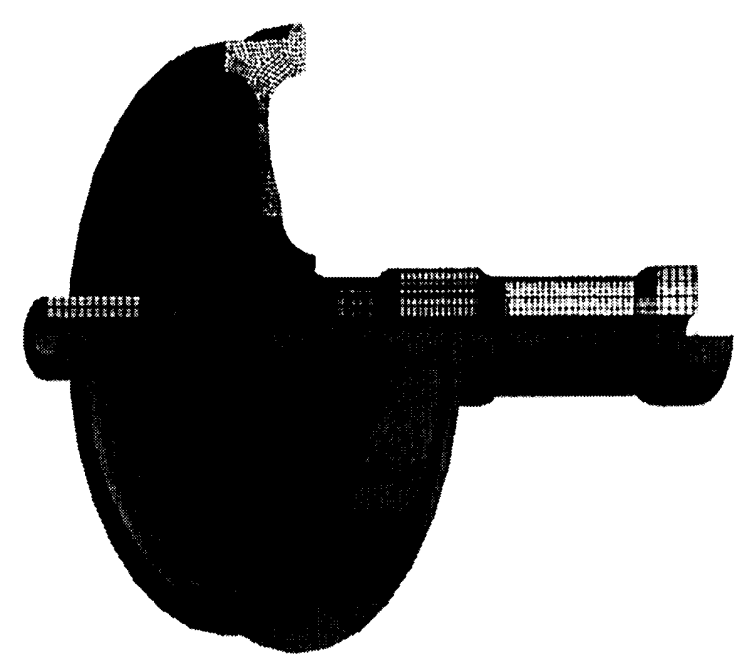

Fig. 1. Solid model and mesh of wheel and axle
Tab.1. Steps to simulate the press fitting of a railway wheel on an axle.

\begin{tabular}{|c|c|c|}
\hline$\underset{\#}{\text { Simulation }}$ & $\begin{array}{l}\text { Axial length of } \\
\text { wheel and axle } \\
\text { contact surfaces } \\
\text { [mm] }\end{array}$ & $\begin{array}{c}\text { Additional } \\
\text { imposed } \\
\text { displacement } \\
{[\mathrm{mm}]}\end{array}$ \\
\hline 1 & 1 & 0.13 \\
\hline 2 & 2 & 0.14 \\
\hline 3 & 3 & 0.15 \\
\hline 4 & 4 & 0.16 \\
\hline 5 & 5 & 0.17 \\
\hline 6 & 6 & 0.18 \\
\hline 7 & 7 & 0.20 \\
\hline 8 & 8 & 0.20 \\
\hline 9 & 9 & 0.20 \\
\hline 10 & 10 & 0.20 \\
\hline 11 & 20 & 0.25 \\
\hline 12 & 30 & 0.25 \\
\hline 13 & 40 & 0.25 \\
\hline 14 & 50 & 0.25 \\
\hline 15 & 60 & 0.3 \\
\hline 16 & 90 & 0.3 \\
\hline 17 & 110 & 0.3 \\
\hline 18 & 120 & 0.3 \\
\hline 19 & 130 & 0.3 \\
\hline 20 & 140 & 0.3 \\
\hline 21 & 150 & 0.3 \\
\hline 22 & 161 & 0.3 \\
\hline 23 & 161 terminated & None \\
\hline
\end{tabular}

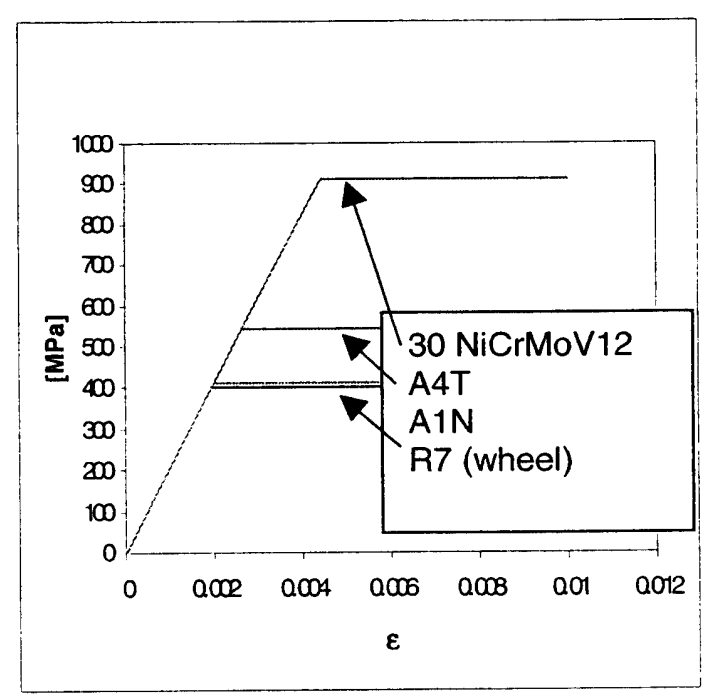

Fig.2. Mechanical characteristics of the different steels employed in the simulations $(\sigma$ : stress $-\varepsilon$ : strain). 


\section{EXPERIMENTAL VALIDATION}

The experimental validation of the FEM model presented in the previous section has been performed within a study focused on the removal of a railway wheel from its seating by means of a hydraulic press [3]. The experimental validation has been performed by comparing the results of the FEM analysis with the measured data referring to an actual experiment made in a workshop of the Milan Transport Authority (ATM Milano), Rolling Stock Maintenance Division.

To study the actual deformations during the wheel removal process, the wheelset has been equipped with strain gauges. The strain gauges were positioned in the lateral surfaces of the wheel bore (roller bearing side), because in that zone there was no interference with the equipment employed during the wheel removal from its seat. The deformations related to the aforementioned surface give meaningful information about the deformations of the contact surfaces.

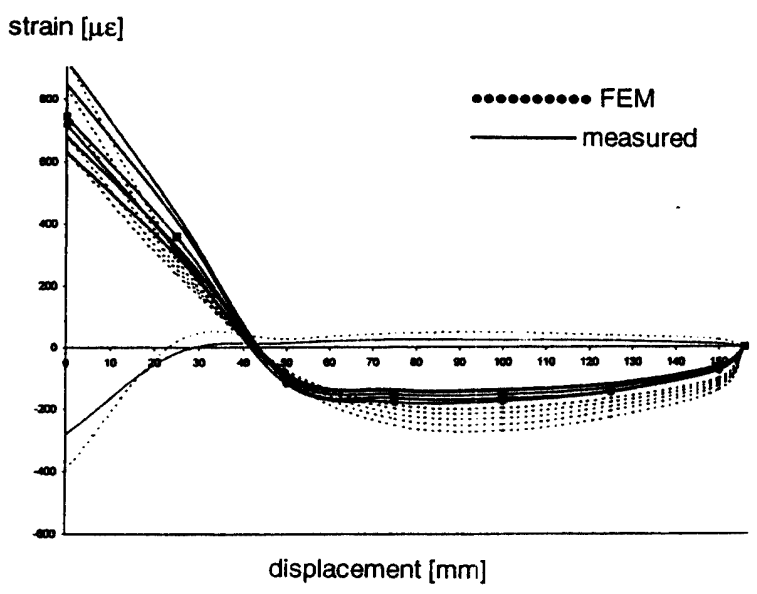

Fig. 3 Comparison between FEM model data and experimental data measured during the removal of a railway wheel from its seat (different curves refer to different strain gauges).

In Fig. 3 a comparison is presented between the filtered experimental data and the data obtained from the finite element model. There is a good agrrement between the experimental data and the and the FEM simulation results. Therefore it is reasonable to state that a finite element model (with axially symmetric elements) can simulate fairly the wheel removal (and of course the press fitting of a railway wheel on its axle).

\section{OPTIMISATION AND 'ROBUST DESIGN'}

The following parameters have been considered during the optimisation and robust design process (Fig. 4) of the wheel and axle assembly.

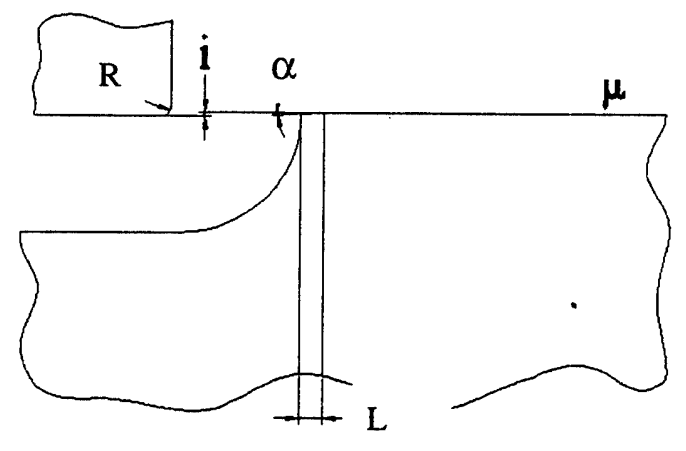

Fig. 4. Geometrical and physical design variables of the press fitting

1. $\mathrm{R}$ fillet radius between the wheel bore and lateral surface $(2<R<4, R[\mathrm{~mm}])$

2. $\alpha$ slope of the conically shaped part of the wheel seat on the axle $\left(3^{\circ}<\alpha<5^{\circ}\right)$.

3. L length of the conically shaped part of the wheel seat on the axle $(5<\mathrm{L}<10, \mathrm{~L}[\mathrm{~mm}])$

4. $\mathrm{i}$ interference between wheel bore and wheel seat on the axle

5. $\mu$ friction (depending on roughness of the mating surfaces and on the kind of lubricant employed)

6. materials: one steel type for the wheel, three steel types for the axle (Fig.2)).

Only the steel grade R7 (as defined by ORE B98[8]) has been considered as the wheel material. The materials taken into account for the axle were three, namely the steel $30 \mathrm{NiCrMoV} 12$ (as defined by UNI 7874), the steel A4T (as defined by ORE [5] [7] [10], characterized by a yield stress of $540 \mathrm{Mpa}$ ) and the steel A1N, (as defined by ORE [5] [7] [10], characterized by a yield stress of 410 Mpa).

The performances of the press fitting that were taken into account were

1. $\sigma_{\mathrm{VM}}$ maximum stress (Von Mises stress, in the axle or in the wheel) during the press fitting process

2. final force $F$ (at the end of the press fitting process maximum force to be imposed through the hydraulic press)

3. $\partial \sigma_{\mathrm{VM}} / \partial \mathrm{i}$ derivative of the stress with respect to the interference between wheel bore and wheel seat on the axle

4. $\partial F / \partial \mathrm{i}$ derivative of the force with respect to the interference.

The maximum stress value of $\sigma_{\mathrm{VM}}$ occurred during the first steps of the press fitting simulation process, (precisely $\sigma_{\mathrm{VM}}$ occurred in the wheel bore just near the fillet and in the wheel seat just rear the conical part towards the axle). In Fig. 5 these highly stressed zones are shown. Plastic deformation occurs in these zones for two 
kinds of steel axle, namely A4T and A1N. The following study has been conducted referring to the steel $30 \mathrm{NiCrMoV} 12$ that is not plastically deformed (at least theoretically).
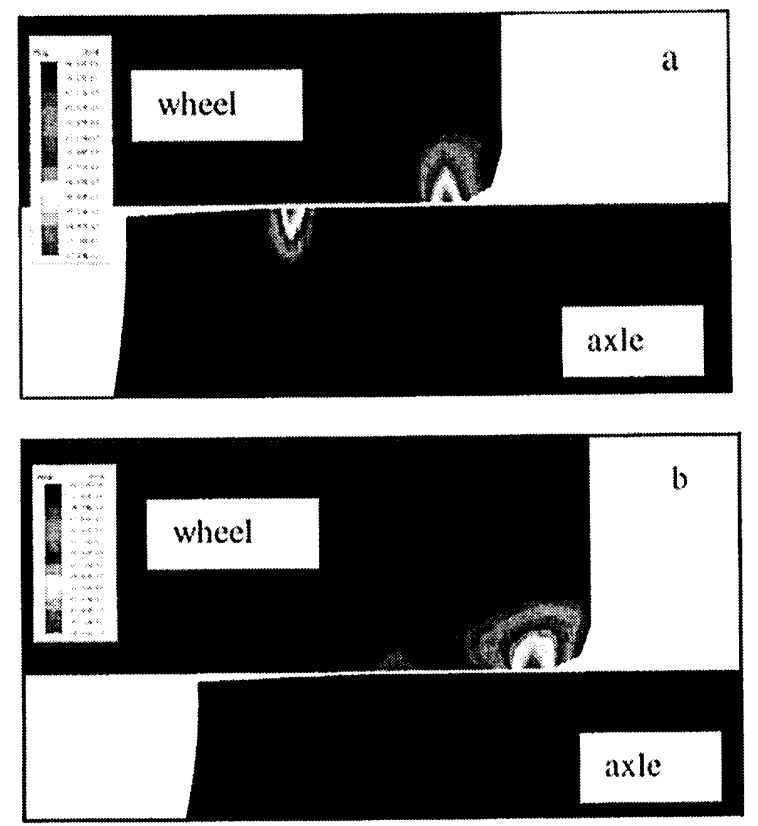

Fig.5. Plastically deformed zones during the press fitting of a wheel (made from steel R7) on two axles made either from steel A1N (a) or from steel 30NiCrMoV12 (b).

The Taguchi method $[14,15]$ has been employed to determine the parameters (design variables) in Fig. 4 which influence mostly the aforementioned performance indexes.

Because there are 4 parameters $(R, \alpha, L, \mu)$ and one noise factor ( $i$, interference), an orthogonal array of type has been used. With reference, respectively, to 2 possible values of the interference, two sets of the 8 design of experiment parameter combinations resulting from the $\mathrm{L}_{8}$ orthogonal array were considered. In this way 16 different parameter combinations were used to perform 16 different FEM simulations. To minimize the performance indexes, a SNR (signal to noise ratio) of SIB (smaller is better) type was adopted. From the analysis of the FEM simulations it turned out that the more influencing parameter on the press fitting force $F$ is the lubricant employed (characterized by the friction rate $\mu$ ); the length of the conical part of the wheel seat on the axle $(L)$ is influencing for less than two orders of magnitude. The more influencing parameter for the maximum Von Mises stress $\sigma_{V M}$ (both on wheel and on axle) is $L$ (the length of the conical part of the wheel seat), followed by the fillet radius of wheel bore $R$. Also the mutual influence of the two aforementioned parameters influence the Von Mises stress.

The Taguchi method allows reaching an optimal and robust solution, but only one performance index at a time can be taken into account. To overcome this restriction of the Taguchi method, a multi-objective robust optimisation has been performed.

Tab. 2. Application of Taguchi method to analyse the press fitting process.

\begin{tabular}{|c|c|c|c|c|}
\hline & $\begin{array}{c}\text { Radius } \\
{[\mathrm{mm}]}\end{array}$ & $\begin{array}{c}\alpha \\
{[\mathrm{deg}]}\end{array}$ & $\begin{array}{c}\mathrm{L} \\
{[\mathrm{mm}]}\end{array}$ & $\mu$ \\
\hline Experiment & & & & \\
\hline 1 & 2 & $3^{\circ}$ & 5 & 0.09 \\
\hline 2 & 2 & $3^{\circ}$ & 10 & 0.12 \\
\hline 3 & 2 & $5^{\circ}$ & 5 & 0.12 \\
\hline 4 & 2 & $5^{\circ}$ & 10 & 0.09 \\
\hline 5 & 4 & $3^{\circ}$ & 5 & 0.12 \\
\hline 6 & 4 & $3^{\circ}$ & 10 & 0.09 \\
\hline 7 & 4 & $5^{\circ}$ & 5 & 0.09 \\
\hline 8 & 4 & $5^{\circ}$ & 10 & 0.12 \\
\hline
\end{tabular}

To perform the said optimisation, a number of response surfaces [19] [20] have been developed to establish the mathematical relationships among $R, \alpha$ and $L, i, \mu$ and the press fitting performances. Various different formulations of response surfaces were evaluated and analysed, particular attention was devoted to the second order response surfaces. To simulate the Von Mises stress $\left(\sigma_{V M}\right)$, the following formula was used

$$
\sigma_{V M}=\cos t+\sum_{i=1}^{5} a_{i} x_{i}+\sum_{i=1}^{5} \sum_{j=1}^{5} b_{j \neq i} x_{i} x_{j}
$$

where $x_{1}=R, x_{2}=\alpha, x_{3}=L, x_{4}=i, x_{5}=\mu$. In Fig. 6 is shown, as an example, the comparison between the data simulated with the response surface and data calculated with FEM model. A good approximation appears for all of the 37 parameter combinations.

By having numerically defined the relationship among the parameters $(R, \alpha, L, i, \mu)$ and press fitting/shrinking performances $\left(\sigma_{V M}, F, \partial \sigma_{V M} / \partial i, \partial F / \partial i\right)$, a multi objective optimisation was performed to find out the optimum parameters $(R, \alpha, L, \mu)$ to be used.

It is worth to state that it is easy to obtain from the following response surfaces

$$
\begin{aligned}
F & =F(R, \alpha, L, i, \mu) \\
\sigma_{V M} & =\sigma_{V M}(R, \alpha, L, i, \mu)
\end{aligned}
$$

the related derivatives

$$
\begin{aligned}
\partial F / \partial i & =\partial F / \partial i(R, \alpha, L, i, \mu) \\
\partial \sigma_{V M} / \partial i & =\partial \sigma_{V M} / \partial i(R, \alpha, L, i, \mu) .
\end{aligned}
$$

The derivatives of $F$ and $\sigma_{V M}$ with respect to $i$ are design robustness indexes.

By means of the response surfaces, 281600 solutions were generated. These solutions were obtained combining the 
feasible values for the design variables (defined within the respective variation ranges, the amplitude of these ranges have been defined as $+/-50 \%$ of the nominal value). Those solutions have been screened to obtain Pareto-optimal (and robust) solutions [21]. In this way 522 Pareto-optimal solutions have been determined.

Among these 522 solutions only three solutions have been selected. For these solutions the FEM simulations have been performed, the expected good correspondence between the data produced by FEM model and data produced by response surface was found.

The Pareto-optimal solution n.203 represents the more robust solution because it is the solution with the lowest values of the derivatives of the force $F$ and of the Von Mises stress $\sigma_{V M}$ with respect to the interference $i$. The Pareto-optimal solution n.203 represents furthermore the solution with the lowest press shrinking force $F$. The Pareto-optimal solution n.126 represents the solution with the lowest values of $\sigma_{V M}$. The values of the parameters and of the performance indexes of the thee optimal solutions are shown in Tab.3.

It is worth to note that the variation of the press fitting force $F$ is mainly influenced by the value of the friction, defined almost entirely by the kind of lubricant used. A decrease of $10 \%$ of the friction implies a subsequent decrease of $10 \%$ for the press shrinking force $\mathrm{F}$ (compare the reference solution and the reference solution with $\mu=0.09$ ). $F$ may be influenced also by the shape of the conical part of the wheel seat on the axle (compare reference solution with solution n.203). The maximum stress $\sigma_{V M}$ does not decrease sensibly by changing the geometric parameters. The optimisation is referred not only to reduce the maximum stress $\sigma_{V M}$, but also to obtain the robustness defined as the insensitivity of both $F$ and $\sigma_{V M}$ to the variation of the interference $i$.

The Figure 7 shows the results of the robust optimisation. Not always the length of the conical part of the wheel seat on the axle must be stretched. The slope of the conic part must be increased. The fillet radius $R$ on the side of

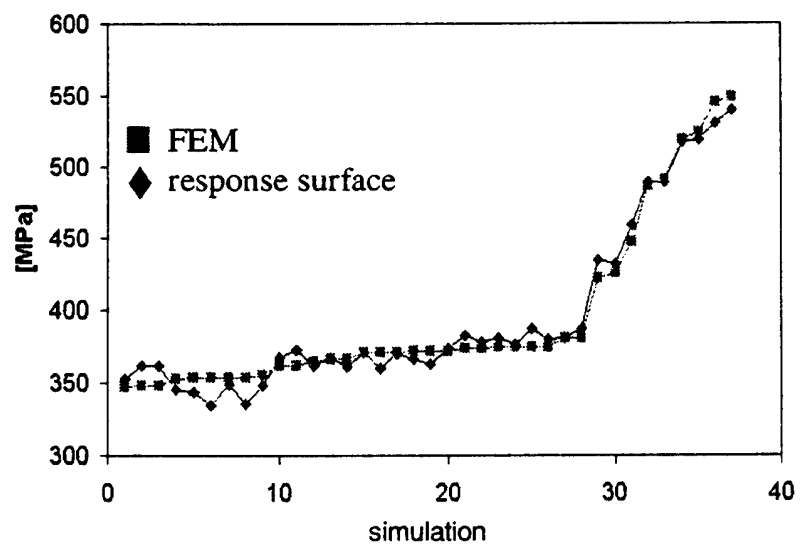

Fig 6. Comparison between Von Mises stress $\sigma_{V M}$ calculated with FEM model and with response surface the wheel bore should always be great.

Tab.3. The three optimal solutions from multi-objective and robust optimisation.

\begin{tabular}{|l|c|c|c|c|}
\hline Solutions & $\begin{array}{l}\text { Radius } \\
{[\mathrm{mm}]}\end{array}$ & $\begin{array}{l}\text { Angle } \alpha \\
{[\mathrm{deg}]}\end{array}$ & $\begin{array}{l}\text { Length L } \\
{[\mathrm{mm}]}\end{array}$ & $\begin{array}{l}\text { Friction } \\
\mu\end{array}$ \\
\hline Reference & 2 & $2^{\circ}$ & 8 & 0.10 \\
\hline $\begin{array}{l}\text { Reference } \\
\text { with } \mu=0.09\end{array}$ & 2 & $2^{\circ}$ & 8 & 0.09 \\
\hline Pareto-opt 33 & 4 & $5^{\circ}$ & 10 & 0.09 \\
\hline Pareto-opt 126 & 2 & $3^{\circ}$ & 10 & 0.09 \\
\hline Pareto-opt 203 & 4 & $5^{\circ}$ & 5 & 0.09 \\
\hline & $\Delta \mathrm{F} \%$ & $\begin{array}{c}\Delta \sigma_{V M} \\
\%\end{array}$ & $\Delta \frac{\partial F}{\partial i}$ & $\Delta \frac{\partial \sigma_{V M}}{\partial i}$ \\
\hline Solutions & & $\begin{array}{c}\text { (mean } \\
\text { interf. })\end{array}$ & - & - \\
\hline Reference & 0 & 0 & - & - \\
\hline $\begin{array}{l}\text { Reference } \\
\text { with } \mu=0.09\end{array}$ & -11 & 0.0 & 0 & 0 \\
\hline Pareto-opt 33 & -16 & -4 & -26 & -10 \\
\hline Pareto-opt 126 & -15 & -5 & -28 & -8 \\
\hline Pareto-opt 203 & -34 & -3 & -32 & -40 \\
\hline
\end{tabular}

Obviously these results comply with the constraints (verified later by calculation) related to the force needed to remove the wheel from its seat and to the fretting wear of the wheel seat on the axle.

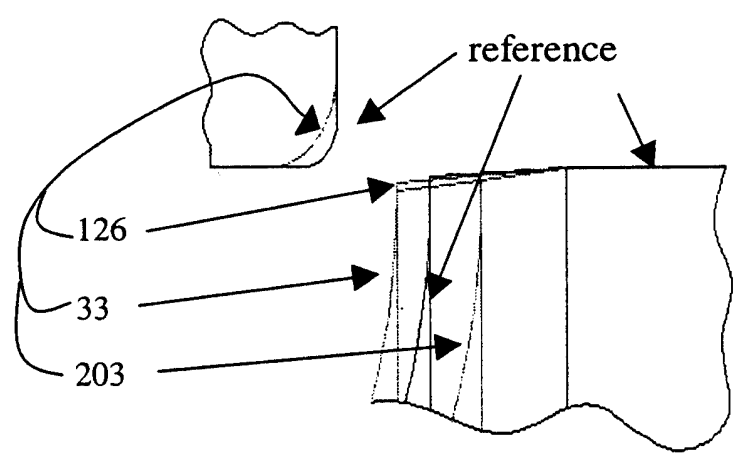

Fig. 7. Sketch of wheel and axle. Comparison between optimal solutions and reference solution.

\section{CONCLUSIONS}

The press fitting process of a railway wheel on its axle has been studied. The final aim is to design the mating contact surfaces of wheel and axle in order to minimize the damage of the wheel seat and of the wheel bore during the relatively frequent operations of press fitting and removal of the wheel from its seating.

Although only an extensive and accurate experimental test campaign may give a reliable contribution to solve the 
addressed problem, in this papaer a preliminary and fundamental contribution has been given to understand the phenomenon of the press fitting (and removal) of a wheel on (from) its axle. The influence of the geometric and physical mechanical parameters (friction lubricant viscosity/contact surfaces roughness) on the stress conditions during the press shrinking phase has been investigated on the basis of a FEM analysis. An experimental verification (related to a removal of a wheel from its seating) has been performed which yielded a positive result. The relationships between the press fit design variables and the performance indexes have been approximated using response surfaces. An optimisation of the design of a wheel and axle in the contact zone (wheel bore and wheel seat on the axle) has been performed. The optimisation has been carried out by taking into account robustness, i.e. the sensitivity of the performance indexes to the value of the interference between wheel bore and axle.

Defining in a correct manner the values of the design variables it is possible to obtain a relatively scarce sensitivity to the machining tolerances (interference), and at the same time, a reduction of the axial thrust and reducted stresses both in the axle and in the wheel. Plastic deformation on the axle can be eliminated (or dramatically reduced) by employing the steel 30 NiCrMoV12.

\section{ACKNOWLEDGEMENTS}

The Authors wish to thank ing. A. Ghidini of Lovere Sidermeccanica S.p.A., Lovere (BG) Italy, for having suggested the research issue dealt with in this paper; Dring. A. Parma of ATM Milano is gratefully acknowledged for the tests performed at ATM-Milano workshop.

\section{REFERENCES}

[1] Lo Conte, A., Mastinu, G., et Al. "Il forzamento albero mozzo per sale ferroviarie" Il progettista industriale Giugno 1998, pp.56-67

[2] Lassi C., Forleo F., Studio con il metodo degli elementi finiti dell'accoppiamento forzato ruota sala ferroviaria, tesi di laurea, A.A. 1994-1995, Relatore: G. Mastinu, Dipartimento di Meccanica, Politecnico di Milano.

[3] Macchiavello R., Indagine teorico-sperimentale sul calettamento forzato ruota-sala ferroviaria, tesi di laurea, A.A. 1997-1998, Relatore: G. Mastinu, Dipartimento di Meccanica, Politecnico di Milano.

[4] ORE, Question B106, Standardisation des voitures, Rapport $n^{\circ} 4$, Essieux montes standard pour voitures, Roulements a rouleaux des boites d'essieux, UIC/ORE, Utrecht, IV 1984.

[5] ORE, Question B136, Essieux montes boites: conception, entretien, standardisation, Rapport no.11, Calcul des essieux-axes de wagons et de voitures, UIC/ORE, Utrecht, IV 1979.

[6] UIC, Code UIC 515, Organes de roulement, UIC, Utrecht, VI 1981.

[7] UIC, Code UIC 813-0, Specification technique pour la foumiture d'essieux montes de materiels roulants moteur et remorqué . Tolerance et montage , UIC, Utrecht, I 1989.

[8] ORE, Question B 98, Standardisation des voitures, Rapport $n^{\circ}, 9$, Roues monoblocs pour le materiel moteur et pour le materiel remorqué, UIC/ORE, Utrecht, IV 1976.

[9] Consiglio Nazionale delle Ricerche, (R. Ciuffi, G. Mastinu et $\mathrm{Al}$ ) Calcolo di verifica del dimensionamento dei collegamenti forzati mozzoalbero, CNR, Bollettino Ufficiale, Norme Tecniche, Anno XXXIII-N.198, 1999.

[10] Priolo G., Santini M., Vari sistemi di calettamento assile-ruota, Atti Congresso Internazionale Rodiggi, Bergamo 1963.

[11] ABAQUS / Standard, version 5.8, User's Manual, vol I, II, III, Hibbitt, Karlsson \& Sorensen, Inc , 1998.

[12] ABAQUS , Theory Manual, Hibbitt, Karlsson \& Sorensen, Inc, 1998.

[13] Zienkiewicz, Z. H., The Finite Element Method, $3^{\text {nd }}$ edition, McGraw-Hill, London 1977.

[14] Kolarik W. J., Creating Quality: Concepts, Systems, Strategies, and Tools, McGraw-Hill, International Editions 1995.

[15] Dean A., Voss D., Design and Analysis of Experiments, Springer 1994.

[16] Belingardi G., Il Metodo degli Elementi Finiti nella Progettazione Meccanica, Levrotto \& Bella, Torino, 1994.

[17] Rijpkema J. J. M., Schoofs A. J. G., Response Surface Approximations for Engineering Optimization, Part I: Concepts and Analysis, Part II: Experimental Design Theory, International Centre for Mechanical Sciences, Eindhoven University of Technology, Department of Mechanical Engineering, Udine, 2000.

[18] Gobbi M., Mastinu G., Doniselli C., Guglielmetto L., Pisino E., Optimal \& Robust Design of a Road Vehicle Suspension System, The Dynamics of Vehicles on Roads and on Tracks, Swets \& Zeitlinger Publishers, Proc. of the $16^{\text {th }}$ IAVSD Symposium - 1999, Suppl. to Vehicle System Dynamics, volume 33.

[19] Beretta S., Capitani R., Citti P., Paolini G., Qualità, affidabilità e sicurezza delle costruzioni meccaniche, Edizioni CUSL Firenze, ISBN 88-8021-045-9.

[20]Belingardi G., Strumenti statistici per la meccanica sperimentale e l'affidabilità , Levrotto \& Bella , Torino, 1996.

[21]Statnikov R. B., Matusov. J. B., Multicriteria optimisation and engineering , Chapman \& Hall, ISBN 0-412-99231-0. 